\title{
RESEARCH
}

Open Access

\section{"Smart" greenhouses and pluridisciplinary spaces: supporting adolescents' engagement and self-efficacy in computation across disciplines}

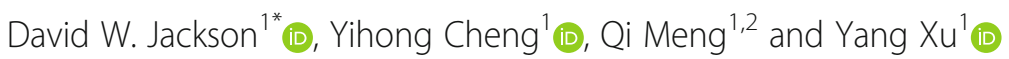

\begin{abstract}
Educational designers are working to embed computation in required classes outside of computer science (CS) courses, to promote equitable access for all students. While many studies embed computation in one discipline, few include projects that substantively involve many disciplines. We conducted a mixed methods case study with a sequential design to explore adolescents' self-efficacy and engagement in computational practices, along with practices in several disciplines of science and engineering. In partnership with two eighth-grade environmental science teachers in a culturally and linguistically diverse urban-ring city of the Northeast US, students $(N=199)$ worked in teams to design, assemble, and code for "smart", or automated, miniature greenhouses. We report on successes in engagement, along with tensions in self-efficacy, namely relating to generality, social factors, and emotive sources. Specifically, we elaborate on tensions related to (1) engagement via fun and camaraderie vs. disaffection per anxiety and stress; (2) practices as sequential vs. simultaneous; (3) prior experience with coding vs. present application; and (4) disciplinary pre-conceptions vs. expansion. We conclude with implications for educational design of pluridisciplinary spaces, especially for those including computation, and which seek to leverage interest and engagement to develop self-efficacy. Also, we discuss how our study extends self-efficacy theory through its finer-grained analyses with more diverse participants. Ultimately, our work builds on and extends current educational designs for embedding computational practices in required, non-CS classes, a vital concern for adolescents' present and future civic participation, in personal, social, and professional ways.
\end{abstract}

Keywords: Pluridisciplinary, Computational thinking, Computational practices, Science and engineering practices, Adolescents, Interest, Student engagement, Self-efficacy

\footnotetext{
* Correspondence: david.jackson@bc.edu

'Boston College, 140 Commonwealth Avenue, Campion Hall \#119A,

Chestnut Hill, MA 02467, USA

Full list of author information is available at the end of the article
}

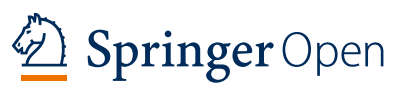

(c) The Author(s). 2022 Open Access This article is licensed under a Creative Commons Attribution 4.0 International License, which permits use, sharing, adaptation, distribution and reproduction in any medium or format, as long as you give appropriate credit to the original author(s) and the source, provide a link to the Creative Commons licence, and indicate if changes were made. The images or other third party material in this article are included in the article's Creative Commons licence, unless indicated otherwise in a credit line to the material. If material is not included in the article's Creative Commons licence and your intended use is not permitted by statutory regulation or exceeds the permitted use, you will need to obtain permission directly from the copyright holder. To view a copy of this licence, visit http://creativecommons.org/licenses/by/4.0/. 


\section{Introduction}

" ... coding, you can make something, like, sciencerelated, like the plants and everything. Maybe engineering. So, I guess it all mixed together." (Gabriella, ${ }^{1}$ post-interview)

Educational designers across the world are trying to find ways to make instruction in computing accessible to all K-12 students, for their present and future thriving in personal, social, and professional endeavors (Allen et al., 2019; Lee \& Malyn-Smith, 2020; Vogel et al., 2017). When considering computational thinking (CT) Denning (2017) argues that educators should focus on CT's manifestation in computational practices, as situated within "domains of interest" to students (p. 38). In this paper, we report on a project that involves at least six disciplines (arts, biology, computer science, construction, physics, and technology) and many domains of interest (coding, construction, cooking, gardening, etc.), extending previous work that tends to focus on one discipline of science.

The disciplines and practices were situated in the learning space of a smart-greenhouse project, wherein eighth graders in a required environmental science course wrote code, worked with design criteria and constraints, and grew plants of cultural relevance for a city with prominent Guatemalan, Haitian, Indian, Irish, Italian, Mexican, and other communities. (See Fig. 1 for an example greenhouse.) As Gabriella noted in the epigraph, students' practices during the unit "all mixed together" amidst disciplines as well as social and individual dynamics. We seek to understand how the grade eight students in a required environmental science class engaged in practices of computation, engineering, and science during the first iteration of the in-school-time, smart-greenhouse project. Guided by our conceptual framework (see Fig. 2), and recognizing the need for additional research on embedding $\mathrm{CT}$ in required classes to reach all K-12 learners, we focused our efforts on the research questions,

(1) What educational tensions, if any, do two dyads of 8th-graders experience during a smart-greenhouse project?

a. What, if any, tensions existed for student engagement?

b. What, if any, tensions existed for practices of science, engineering, and computation?

(2) How, if at all, did students develop their selfefficacy in computation, engineering, and science?

${ }^{1}$ All city, school, student, and teacher names are pseudonyms.

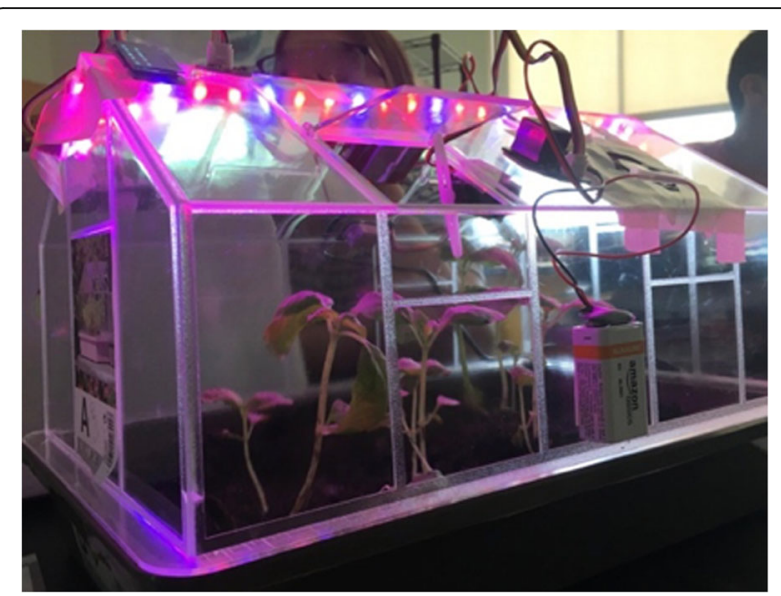

Fig. 1 A typical example of a completed smart greenhouse. The lights, microcontroller, and battery are placed on the exterior, whereas plants, sensors, and most actuators (fans, pumps, etc.) reside in the interior

\section{Conceptual framework}

In the present study we adopt the lens of self-efficacy theory (Bandura, 1977, 1993, 2001, 2006), given an assumption that socioemotional factors like attitudes, identity, and interest tend to be more salient for long-term outcomes than do achievement scores or course grades (Fortus \& Touitou, 2021; Maltese \& Tai, 2011; Nguyen \& Riegle-Crumb, 2021; Tytler \& Osborne, 2012). We inferred that a pluridisciplinary approach (Hofstetter, 2012) could support student engagement (Fredricks et al., 2004, 2016), which in turn would foster self-efficacy (Bandura, 1977; Schunk \& DiBenedetto, 2016). Namely, student interests in arts, biology, computer science, construction, physics, and technology could promote participation in computing practices (i.e., engagement), making it easier for students to learn in the short-term, to develop selfefficacy over the long-term.

\section{Self-efficacy theory}

Self-efficacy theory positions individuals and groups as agents of change, while at the same time asserting that environments and behavioral patterns are also effecting change, in a "triadic reciprocal" relationship (Bandura, 2001, p. 14). That is, individuals/groups (personal), their surroundings (environments), and their actions (behaviors) all influence each other. Self-efficacy is linked with mediators and outcomes such as student engagement, achievement, course choice, and career selection (Bandura, 1993, 2001; Schunk \& DiBenedetto, 2016). Though there has been much work recently on self-efficacy in computation, there remains a need for work in more culturally and linguistically diverse settings, especially research that goes beyond pre-post models, to capture the complex processes of self-efficacy development (Schunk \& DiBenedetto, 2016). 


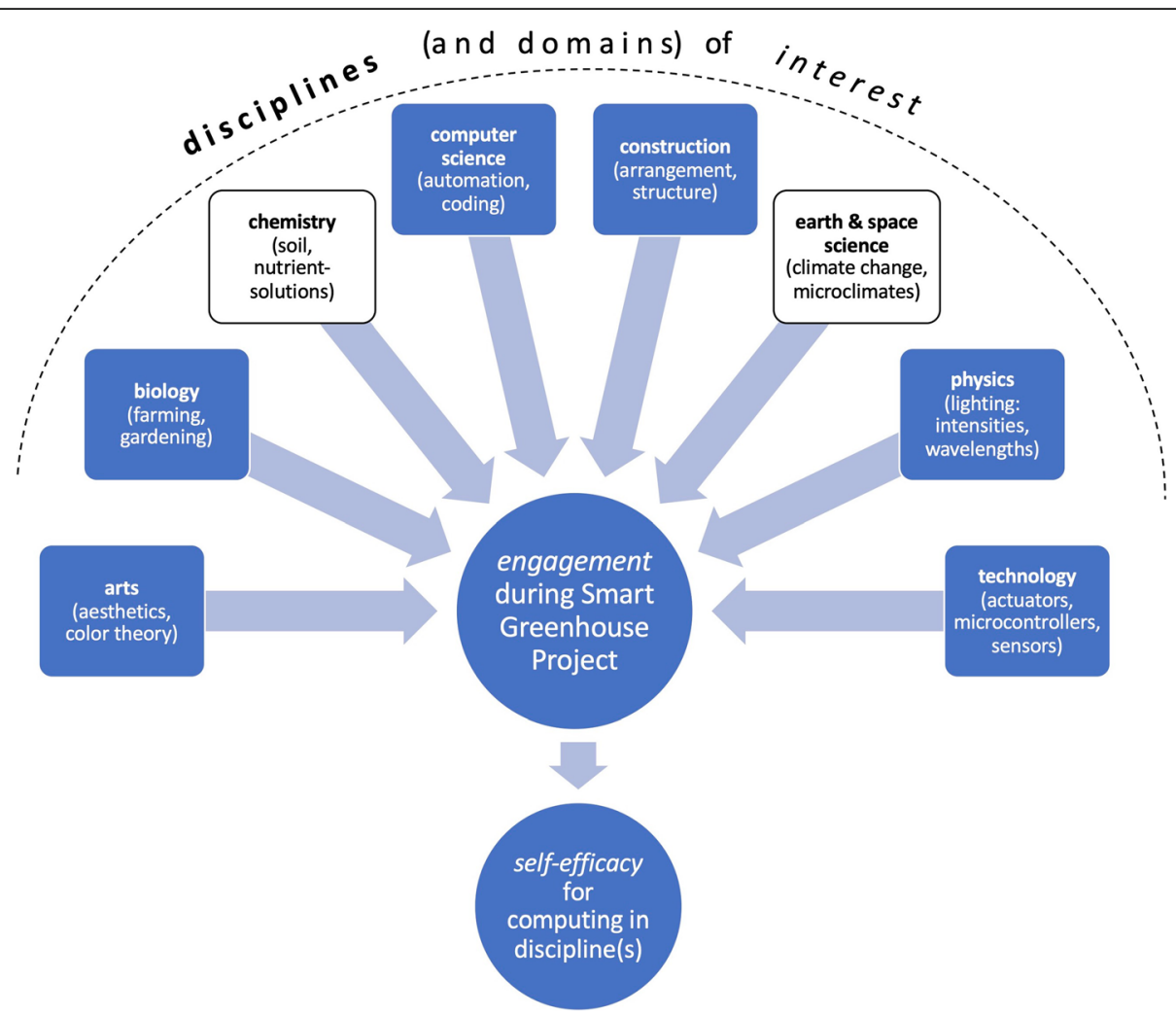

Fig. 2 Our conceptual framework for studying adolescents' practices of computing, engineering, and science. At least six disciplines were pluralistically represented in the project, with two more disciplines (chemistry and earth \& space science) emphasized in other implementations (Asante et al., 2021). In general, pre-existing interest in one or more discipline(s) supports engagement in the project, which in turn promotes self-efficacy for computing in discipline(s)

Self-efficacy is "people's beliefs in their capabilities to produce given attainments" (Bandura, 2006, p. 307). It can be influenced by "enactive, vicarious, exhortative, and emotive sources" (Bandura, 1977, p. 191), related to phenomena such as performance accomplishments, vicarious experience, verbal persuasion, and emotional arousal. Self-efficacy is processed through a variety of social, situational, and temporal contexts. For example, other persons' reactions, presence or absence of safeguards, and differential persistence of various interventions (e.g., of direct vs. symbolic experiences) all effect the expression of self-efficacy. Dimensions across which self-efficacy can vary include its magnitude, generality, and strength. For instance, the educational intervention of a coding project for different students could result in greater or lesser changes in self-efficacy, the degree to which it applies in different disciplines (e.g., coding in science vs. coding in humanities), and the durability of the changes (i.e., resistance to fading over time).

\section{Student engagement}

Student engagement is generally conceptualized over shorter timescales than is development of self-efficacy. There remains considerable debate about student engagement, including its scale (e.g., individual or group) and its relationship with theories of motivation and self-regulated learning (Boekaerts, 2016). For now, it appears that a threepart model by Fredricks et al. (2004) remains the most influential (Christenson et al., 2012), wherein student engagement is considered to have affective/emotional, behavioral, and cognitive dimensions, essentially related to feeling, doing, and thinking, respectively. It should be noted that Fredricks et al. (2016) have since explored social engagement, which relates to how individuals participate in paired, small-group, or full-class academic interactions.

\section{Interest}

We sought to promote student engagement (and ultimately self-efficacy) by building on students' interests. Our hopes were grounded in the well-established links between interest, engagement, motivation, and self-efficacy (Järvelä \& Renninger, 2014; Luo et al., 2021; Vongkulluksn et al., 2018). We followed the Four-Phase Model of Interest and Development by Hidi and Renninger (2006), in which interest develops from triggered situational interest, maintained situational interest, emerging individual interest, and well-developed individual interest. For example, seeing an LED light strip in rainbow colors might result in "short-term changes in 
affective and cognitive processing" (triggered situational interest; p. 114) for a student, such as an affinity for the technology and a curiosity about how to manipulate the colors. If the student continues to learn about the LED strip and develops proficiency in controlling it over a longer period of time, then that student has maintained situational interest. Subsequently, if the student voluntarily works with LED light strips during lunch or afterschool, then the student holds emerging individual interest. Finally, if the student asks to take the LED light strip home after the end of the project or seeks out additional classes, clubs, or camps, then the student has well-developed individual interest. We hoped that our pluridisciplinary approach would both draw on students' preexisting individual interests and introduce students to some new, situational interests, which may or may not subsequently develop into new individual interests.

\section{Literature review: integrating computational thinking (CT) into required coursework}

Since Wing's (2006) seminal revival of computational thinking (CT), initially pioneered by Papert (1980), CT has been framed by a variety of private and public institutions, in terms of attitudes, core concepts, dispositions, habits, practices, processes, and skills. Several CT frameworks have gained popularity in recent years; for this project, we based our work primarily on a review by Grover and Pea (2013), as detailed by our analytical framework in the Methods section. In this section, we first review the extant literature on embedding $\mathrm{CT}$ in required classes for $\mathrm{K}-12$ learners. Then we survey scholarly writings on CT for smart-greenhouses, which to date have been predominantly in tertiary or informal education settings. We argue that our paper builds on previous work that took in-depth approaches to single disciplines, and extends the scholarly base in more pluridisciplinary ways.

Most work has been conducted in classrooms that focus on one discipline within science, technology, engineering, and math (STEM), although computational thinking also shows promise for the arts and humanities (Denning, 2017; Grover \& Pea, 2018; Voogt et al., 2015; Wing, 2006). Recent efforts at embedding computational thinking in non-CS classrooms have been unified under the banners of "STEM-C" or "STEM $+C$ ", denoting STEM with computing. One particularly successful project involves agent-based modeling with required highschool science classes in metropolitan Chicago, US, especially in the discipline of biology (Wilensky et al., 2014). High-school physics can also be a fruitful subject in which to embed CT, as evidenced by a project-based learning approach from Shin et al. (2021). In terms of out-of-school-time learning with high schoolers, one study found small to large gains in CT self-efficacy for a two-summer total of 35 students completing Making activities in "a public library of a large Midwest [US] city" (Yin et al., 2020, p. 195), also developing instruments to measure decomposition, abstraction, algorithmic thinking, and pattern generalization.

With students in grades 3-5, Century et al. (2020) found synergies between science, social studies, and English Language Arts (ELA), when they took care to align a problem-based social-studies units, such as one on invasive species in Florida, US. In another elementary-school study, Wei et al. (2021) in northern China used an experimental study to find that partial pair programming - where students first work together, then individually complete final products - showed improvements in CT for boys in boy-boy groups and girls in girl-boy groups. In a study with elementary schoolers in the Canton of Vaud, Switzerland, robotics showed promise at integrating computational thinking into non-CS classes (Chevalier et al., 2020).

At the middle-school level, Rosen et al. (2016), based in Georgia, US, have created three different design courses to integrate STEM+C concepts through projectbased inquiry learning in engineering. Also, in Massachusetts, US, Tucker-Raymond et al. (2019) used critique of computer games to facilitate students' participation and engagement in learning about climate change. Despite the success of exemplars listed here, more empirical work is needed to understand how to embed CT in a variety of interdisciplinary settings (Grover \& Pea, 2018; Voogt et al., 2015).

Post-secondary, informal, and industry organizations are exploring the benefits of semi- or fully-automated greenhouse management systems (e.g., Birsan et al., 2017; Christopher, 2013; Hernandez, 2018). However, to our knowledge, no projects have yet examined the use of smart greenhouses in required K-12 classes. In-schooltime interventions are vital to reach all learners, as outof-school-time programs are affected by self-selection of individuals who are already interested in STEM fields, though they also may close some gaps related to gender and race/ethnicity (Allen et al., 2019).

\section{Methods}

In this study we conducted a comparative mixed methods case study with a sequential design (Creswell \& Plano Clark, 2018), using quantitative methods for selecting participants then qualitative methods for analyzing the experiences of student-teams. In comparing two cases, we arrived at deeper understandings as we made sense of similar and different data generated from a variety of sources.

\section{Setting and participants}

Central Middle School is one of two, grades 6-8 schools in Mills City, an urban ring city in the Northeast US. 
Table 1 Racial and ethnic data for 192 participants who self-identified (of 199 total participants)

\begin{tabular}{lllllll}
\hline $\begin{array}{l}\text { African, African- } \\
\text { American, Black }\end{array}$ & $\begin{array}{l}\text { Asian, Asian- } \\
\text { American }\end{array}$ & $\begin{array}{l}\text { Caribbean, Black (ex: } \\
\text { Haitian, Jamaican) }\end{array}$ & $\begin{array}{l}\text { Hispanic } \\
\text { or Latinx }\end{array}$ & $\begin{array}{l}\text { White (non-Hispanic), Anglo, } \\
\text { Caucasian, European }\end{array}$ & $\begin{array}{l}\text { 2+ races / ethnicities } \\
\text { (please specify) }\end{array}$ & $\begin{array}{l}\text { Other } \\
\text { (please } \\
\text { specify) }\end{array}$ \\
\hline $12(6 \%)$ & $8(4 \%)$ & $9(5 \%)$ & $75(39 \%)$ & $69(36 \%)$ & $15(8 \%)$ & $4(2 \%)$ \\
\hline
\end{tabular}

Mills City is a culturally and linguistically diverse city, including many speakers of English, Haitian Creole, and Spanish, with major waves of immigration from Europe in the mid-1800's and Latin America and the Caribbean in recent decades. In addition to current immigration, there is gentrification, especially in defunct mills being converted into luxury apartments.

We worked with two teachers and 199 students in grade-eight environmental science. For gender, $193 \mathrm{stu}-$ dents self-identified, $49 \%(N=94)$ as female, $49 \%(N=$ 95) as male, and $2 \%(N=4)$ as non-binary. Racial and ethnic data are presented in Table 1. School-wide, about $50 \%$ of students learned a language before learning English, about $10 \%$ were classified as having limited proficiency in English, about 20\% received special education services, and about $30 \%$ were classified as "economically disadvantaged" per state data.

The two cooperating teachers, Mr. Hanrahan and Ms. Petralia, were in their third year working together at Central Middle School. Both teachers are white-coded, though Mr. Hanrahan self-identified as multiracial (Black and White). This intervention was the first time that either Mr. Hanrahan or Ms. Petralia had endeavored to teach computational thinking practices through coding, and they were both beginning programmers.

Considering the complexity of physical computing and the lack of related training in science teacher preparation programs, the research team conducted professional development to support science teachers in meaningfully integrating physical computing into their classrooms (Gendreau Chakarov et al., 2019). The fourth author planned and led approximately five hours of preintervention professional development. The sessions consisted of guided practice, with teachers completing activities that students would later encounter. During implementation, the research team provided at least one teaching assistant, and usually one or two observers as participants (Creswell, 2013), during any given class period. We made this design choice to ensure that Mr. Hanrahan and Ms. Petralia had sufficient support given the limited time we had for professional development.

Throughout the pre-intervention professional development, we kept track of their learning progression and documented major challenges they encountered. The two teachers took very different approaches to making sense of how the smart greenhouse works as a complex system. Mr. Hanrahan took a more simultaneous, holistic approach as he focused on learning about all functions of the smart greenhouse before moving on to learn about codes for each function. His approach sought to "encourage play and failure" (Hadad et al., 2020, p. 164), as students could brainstorm different configurations and criteria, even before they could test the feasibility of what they brainstormed. On the other hand, Ms. Petralia's approach was a more sequential, analytic approach, as she first dived deeply into exploring codes for one function, and would not move on to the next function until she felt confident (Xu, 2019). Her approach was more targeted towards "continually assessing student understanding, and scaffolding learning based on that assessment" (Hadad et al., 2020, p. 164), reflecting a priority on "helping ... students be academically successful" (Ladson-Billings, 1995, p. 477). Together, Mr. Hanrahan, Ms. Petralia, and the fourth author were able to form a community of learners (A. J. Rodriguez, 2015) as they trusted each other and respected their different learning styles, resulting in some adjustments to build on each others' strengths (Xu, 2019).

\section{Curriculum design}

The Innovation in Urban Science Education (IUSE) lab led the development of the smart greenhouse hardware, software, and instructional materials. Lesson plans are available online at <https://growthings.readthedocs.io/ en/latest/index.html $>$. The fourth author crafted a sequence of guided activities based on the Wio Link microcontroller, the EsPy integrated development environment (IDE) for the MicroPython programming language, and a variety of add-on components (light sensors, temperature-and-humidity sensors, light strips, fans, etc.). MicroPython can run on relatively inexpensive hardware, yet has robust functionality including interaction with the "Internet of Things". The hardware and software were integrated into a plastic greenhouse about $38 \mathrm{~cm}$ long, $24 \mathrm{~cm}$ wide, and $17 \mathrm{~cm}$ tall (see Fig. 1). Choosing plants that we thought would have cultural relevance, we gave students the option of growing basil, cilantro, lettuce, or a combination of any two. In addition to "integrating the students' lives and culture" (Hadad et al., 2020, p. 164), the choice of plants "helped students to be ... culturally competent" (Ladson-Billings, 1995, p. 477) through exposing members of various ethnic groups to prominent herbs in each others' cuisines. Further, there was potential to donate plants to the school cafeteria or a local food assistance program, explicitly "connecting students to resources ... outside the 
Table 2 Overview of smart-greenhouse curriculum sequence

\begin{tabular}{ll}
\hline Day(s) & Topic(s) \\
\hline 1 & $\begin{array}{l}\text { Brief introduction to "smart" (automated) greenhouses, } \\
\text { microcontrollers, and the MicroPython programming language }\end{array}$ \\
$2-3$ & $\begin{array}{l}\text { How light affects plant growth, and how to monitor and } \\
\text { control light }\end{array}$ \\
$4-6$ & $\begin{array}{l}\text { How temperature and humidity affect plant growth, and how } \\
\text { to monitor and control temperature and humidity; includes } \\
\text { activity that links variations in light, humidity, and temperature }\end{array}$ \\
$7-9 \quad \begin{array}{l}\text { Using engineering design principles to construct a working, } \\
\text { miniature, "smart" greenhouse }\end{array}$ \\
Showcase for schoolmates, administrators, and community \\
members
\end{tabular}

classroom" (Hadad et al., 2020, p. 164) and supporting students in being more "sociopolitically critical" (Ladson-Billings, 1995, pp. 477-478) with respect to topics like food deserts and food (in security (Asante et al., 2021).

The IUSE lab planned for 10, 56-min class periods, with the final period consisting of a community Showcase. The curriculum had four subunits, as shown in Table 2. Throughout the project students worked in teams of two or three. Because of make-up days for weather cancellations, we expanded to 13 class-periods, allowing extra time for remediation or enrichment.

Overall, we designed the smart greenhouse curriculum to help students integrate computational thinking and practices with core concepts in several science subjects. Namely, we considered science and engineering practices per the Next Generation Science Standards (NGSS; NGSS Lead States, 2013) and computational thinking elements per Grover and Pea (2013). The smart greenhouse curriculum challenged students to obtain, evaluate, and communicate information about biology to identify environmental factors that would impact plant growth, namely light, air temperature and humidity, air flow, and more. The biology-situated practices enabled the students to program the appropriate sensors and actuators, using abstractions and pattern generalizations, as well as algorithmic notions of flow control. Also, students needed to plan and carry out investigations in physics to properly wire the circuits required to power the exhaust fans in their smart greenhouses, which would also enable them to tell the difference between coding and wiring errors, thereby engaging in debugging and systematic error detection. Further, students needed to incorporate logic with Python, or use math and computational thinking, to make sense of and correctly apply if-then-else loops, a type of conditional logic, that would allow sensors and actuators to control environmental factors within an ideal range for plant growth.

\section{Research Design \& Data Generation}

We used a mixed-methods design, namely a convergent design that included participant selection for explanation (Creswell \& Plano Clark, 2018). A summary is provided in Fig. 3.

In Phase 1 (participant selection for explanation) we used pre-survey results to identify students who scored well-above-, nearly-at-, or well-below-average for computer science (CS) interest and confidence, which are related to self-efficacy in primarily emotive and situational ways (Bandura, 1977). We sampled for maximum variation (Creswell \& Plano Clark, 2018) to focus our data generation on student-teams with high or low levels of CS interest and confidence, as well as a balance of teams between the two classroom teachers. In total, we followed eight student-teams, one per class per teacher. Only four teams orally consented to be audio- or video-recorded, despite all having returned written permission forms. Thus, our final data corpus and analysis are limited by convenience sampling (Creswell \& Plano Clark, 2018).

In Phase 2 (explanation), we first focused on the transcripts of three rounds of interviews we conducted with the four focal students, including a pre-interview before

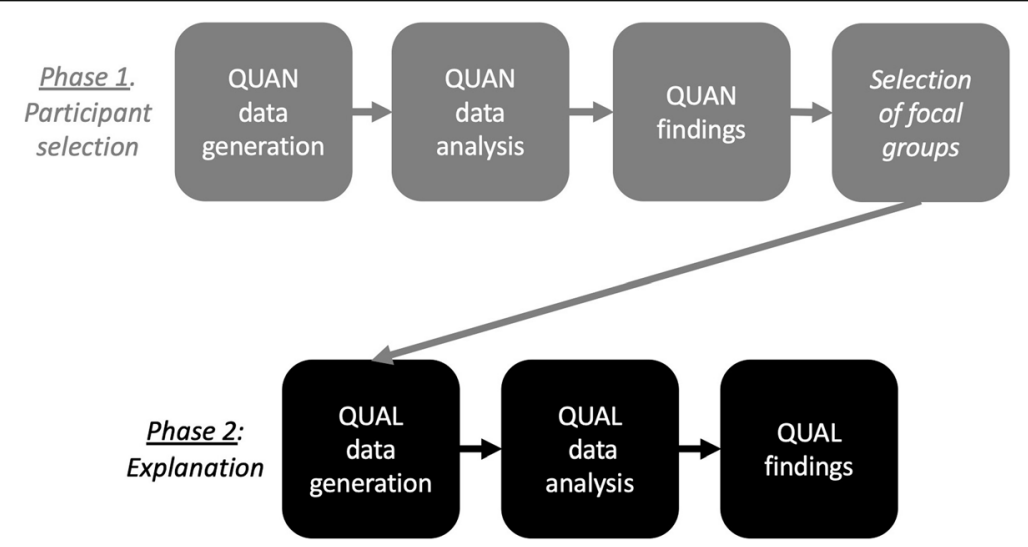

Fig. 3 Mixed-methods sequential design, including participant selection followed by explanation 
they began to experience the curriculum, a postinterview after they finished assembling and programming their smart greenhouses, and a follow-up interview several months after the post-interview. All interviews were semi-structured to give students the freedom to speak extensively about their experience, with the interviewers following-up with probing questions as needed. Second, based on findings made from our preliminary analysis of the interview transcripts, we located video clips of a series of key moments captured by cameras set up in the classrooms that captured students' conversations, body language, and more. Third, based on the video clips selected, we extracted the corresponding screen recordings of coding work, which indicated what was happening in the focal students' coding software when they were engaged in the key moments. Qualitative data sources are shown in Table 3, and interview questions are listed in Table 4.

\section{Our analytical framework for student practices}

As mentioned in the conceptual framework, we view interest, engagement, and self-efficacy through students' practices in various domains and disciplines. We concur with the NGSS (NGSS Lead States, 2013) that engaging in practices "requires not only skill but also knowledge that is specific to that practice" (p. xv). The NGSS constitute most of our framing of engineering and science practices, though we supplement them with Rodriguez's (2015) dimension of engagement, equity, and diversity practices.

During the first round of coding, we followed Grover and Pea's (2013) computational elements, which we abbreviate as abstractions, algorithms, conditionals, debugging systematically, efficiency and performance, iterative/ recursive/parallel, modularizing, processing, and symbols. Given our partnership with a public school in Massachusetts, in the second round of coding we added computational practices of the Massachusetts Digital Literacy and Computer Science Framework (MA DLCS; Massachusetts Department of Elementary and Secondary Education [MA DESE], 2016).

\section{Data analysis}

As mentioned earlier, we focused on two student-teams through a combination of sampling for maximum variation and convenience (Creswell \& Plano Clark, 2018). Quantitative analysis was performed by Amy Semerjian, a colleague in the IUSE lab, using Statistical Package for Social Sciences $\left(\mathrm{SPSS}^{\circ}\right)$. Because only roughly $50 \%$ of students completed the post-survey, including just one of the four focal participants, we omit post-survey analyses from this article. Qualitative analysis (QUAL) was conducted by the first three authors. We used Dedoose, an online platform where we uploaded interview transcripts and classroom videos. We then performed highlighting on lines in the transcripts or episodes of the videos that we found representative (Erickson, 2006), and finally discussed our choices in a series of 11 weekly meetings.

Our analysis started by examining the quantitative data from pre- and post-surveys. We then coded preand post-interviews of the two focal teams of two students each, using both deductive coding per our conceptual and analytical frameworks, as well as inductive coding per phenomena that resonated with emerging findings (Miles et al., 2014). In addition to process and emotion codes, we included in vivo codes, especially for students' epiphanies (Creswell, 2013). In these ways, our analysis included both phenomenological and narrative qualities (Creswell, 2013).

After coding interviews, we began analysis of data generated from video (Erickson, 2006) for the two focal teams. We analyzed one computation-intensive class period and one engineering-intensive class period for each of the two teams. Erickson's (2006) "whole-to-part, or inductive, approaches" (p. 183) helped us focus on four salient episodes of about $3-5$ min each, transcribing nonverbal as well as verbal elements. During follow-up interviews $(\sim 12 \mathrm{~min}$ each) conducted four months after the intervention, we watched one video episode each with two of the participants (one per focal team).

Upon completion of video analysis, we transcribed and open coded (Creswell, 2013) field notes for the four episodes. We then transcribed and open coded students' final written reflections. After that, we transcribed and coded our conversations of the follow-up interviews. Our final phase of data analysis was compiling our findings into tables for cross-case analysis, firstly in a caseoriented approach (i.e., for each team) and secondly in a variable-oriented approach (i.e., comparing and contrasting teams with each other) (Miles et al., 2014). For deductive codes we began with four for self-efficacy (affective, cognitive, motivation, and selection), three for engagement (affective, behavioral, and cognitive), and 20

Table 3 Qualitative data sourcing during Phase 2

\begin{tabular}{llllll}
\hline Interviews & $\begin{array}{l}\text { Field } \\
\text { notes }\end{array}$ & $\begin{array}{l}\text { Audio- } \\
\text { only }\end{array}$ & $\begin{array}{l}\text { Video from camera } \\
\text { (with audio) }\end{array}$ & $\begin{array}{l}\text { Video from screen } \\
\text { capture (with audio) }\end{array}$ & Work samples (from all participating students) \\
\hline 14 pre-, 17 post-, 2 & $\begin{array}{l}54 \\
\text { pages }\end{array}$ & $20 \mathrm{~h}$ & $20 \mathrm{~h}$ & $10 \mathrm{~h}$ & $\begin{array}{l}\text { "Do-Now" responses, project-planning worksheets, in- } \\
\text { terim reflections, final reflections }\end{array}$ \\
follow-up & & & & (w) \\
\hline
\end{tabular}

Note. Roughly one-fourth of the data above were coded in this study, for the two focal-groups 
Table 4 List of interview questions

pre What comes to mind when you hear the word "coding"?
2. Have you done coding before? Can you tell me about it?
3. Are you interested in coding? Why or why not?
4. What do you think coding can do? What do you want to do with coding?
5. What kind of jobs do you think involve coding? Can you provide a couple of examples?
6. Do you think scientists do coding in work? Why or why not?
1. What do you think you have learned from the smart greenhouse project?
2. Could you tell me how your greenhouse works?
3. Can you tell me about a problem you ran into while you were coding? How did you fix that problem?
4. Now you have completed the project, do you see yourself wanting to learn more about coding? Why?
5. What else do you think you can do using the science and coding you have learned?
6. When you heard that you were going to do a coding project, what did you think? Has this perception changed? Why or why not?
7. Do you want to take your greenhouse home? Why? What else would you like to do with it?
8. Do you think scientists do coding in work? Why or why not?
9. Did you tell anyone at home about the project? If yes, who? How did you describe it to them?
1. How, if at all, did the project make you feel engaged, in thinking, feeling, and doing?
2. Which people, documents, etc., did you think were useful supports? Which provided too much or too little support?
3. What practices of computation, engineering, and science did you do? How much were those practices separate (one-at-a-time), and
how much were those practices together (more-than-one-at-a-time)?
up

for practices (eight for NGSS, nine for computing, eight for disciplines, and three of equity, engagement, and diversity). During analysis, two additional codes for practices emerged, namely whether practices from different disciplines were viewed by students as sequential or simultaneous. In considering both the frequency and patterns of codes (Saldaña, 2009), we focused on 26 codes described in Table 5.

\section{Results}

\section{Overview of findings}

We found four main tensions (Research Question \#1), primarily for generality, and for emotive and social factors (Research Question \#2), as students used pluridisciplinary approaches to engage (Research Question \#1a) in practices of computation, engineering, and science (Research Question \#1b). The four tensions are (1) engagement via fun and camaraderie vs. disaffection per anxiety and stress; (2) practices as sequential vs. simultaneous; (3) prior experience with coding vs. present application; and (4) disciplinary pre-conceptions vs. expansion (see Table 6). Of the eight teams we followed, we present data from two teams per convenience and maximum variance sampling (Creswell, 2013).

\section{Findings from phase 1 (participant selection model)}

As shown in Table 7, teammates' comfort, skill, and interest, per seven-point Likert-style items on the presurvey, were not always aligned. It might seem counterintuitive that an adolescent could be interested and $u n$ comfortable, but self-efficacy theory suggests that vicarious and exhortative sources can offset emotive sources (e.g., a student who aspires to be like, and is encouraged by, a role model might persist through initial frustration with a new skill).

Table 5 Focal codes for final cross-case analysis

\begin{tabular}{|c|c|c|}
\hline Category & Focal codes & Examples \\
\hline Self-efficacy & $\begin{array}{l}\text { expectational: enacted, vicarious, exhortative, emotive, } \\
\text { magnitude, generality, strength; } \\
\text { personal: social, situational, temporal }\end{array}$ & $\begin{array}{l}\text { "... we had some trouble, but we know that if we had more time, we } \\
\text { could have figured it out." -Faith \& Taylor, final reflection }\end{array}$ \\
\hline Engagement & affective, cognitive, behavioral & $\begin{array}{l}\text { "I guess [coding] is really fun, and I really enjoy it in my free time." -Clara, } \\
\text { pre-interview }\end{array}$ \\
\hline Disciplines & $\begin{array}{l}\text { arts, biology, chemistry, computer science, construction, } \\
\text { earth \& space science, physics, technology }\end{array}$ & $\begin{array}{l}\text { "controlling experimenting with the plants, what they do, what they will } \\
\text { come out to be." -Gabriella, post-interview }\end{array}$ \\
\hline Practices & $\begin{array}{l}\text { communicating, designing, personal relevance, sequential, } \\
\text { simultaneous }\end{array}$ & $\begin{array}{l}\text { "connections with family experiences (grandma as gardener, e.g.)" -field } \\
\text { notes, } 2018 \text { June } 8\end{array}$ \\
\hline
\end{tabular}


Table 6 Tensions in student practices, from variable- and case-based analyses

\begin{tabular}{|c|c|c|c|}
\hline Tension & Clara \& Gabriella & Faith \& Taylor & $\begin{array}{l}\text { Self-efficacy } \\
\text { connection }\end{array}$ \\
\hline $\begin{array}{l}\text { 1. engagement via } \\
\text { fun and camaraderie } \\
\text { vs. } \\
\text { disaffection per } \\
\text { anxiety and stress }\end{array}$ & $\begin{array}{l}\text { - Laughing about minor mistakes } \\
\text { - Focus on aesthetics } \\
\text { - Checking partner's work } \\
\text { - Helping paired-group }\end{array}$ & $\begin{array}{l}\text { - Playing with materials, talking about socializing } \\
\text { - Providing emotional support } \\
\text { - Concerns about grade-anxiety and test-stress }\end{array}$ & $\begin{array}{l}\text { emotive (for } \\
\text { expectational } \\
\text { change) }\end{array}$ \\
\hline $\begin{array}{l}\text { 2. practices as } \\
\text { sequential } \\
\text { vs. } \\
\text { simultaneous }\end{array}$ & $\begin{array}{l}\text { - Began with one set of canonical practices per } \\
\text { day } \\
\text { • Ended with "different mixes", operationalized } \\
\text { as "10 min [at a time]" }\end{array}$ & $\begin{array}{l}\text { - Connected engineering with science, but not } \\
\text { computing } \\
\text { - Worked in parallel (e.g., one completing a science } \\
\text { worksheet, other writing code) }\end{array}$ & $\begin{array}{l}\text { generality (for } \\
\text { expectational } \\
\text { change) }\end{array}$ \\
\hline $\begin{array}{l}\text { 3. prior experience } \\
\text { with coding } \\
\text { vs. } \\
\text { present application }\end{array}$ & $\begin{array}{l}\text { - Previous computational experience in grade } \\
\text { six class and after-school club } \\
\text { - Minimal use of TA, who nonetheless used } \\
\text { Socratic questioning amidst errors } \\
\text { - Rapidity of coding, at expense of consistency } \\
\text { with science }\end{array}$ & $\begin{array}{l}\text { - Previous computational experience in grade six class } \\
\text { only } \\
\text { - Frequent use of TA, often in a confirmatory manner } \\
\text { - Quickness to claim broken items, rather than engage } \\
\text { in troubleshooting }\end{array}$ & $\begin{array}{l}\text { social (for personal } \\
\text { change) }\end{array}$ \\
\hline $\begin{array}{l}\text { 4. disciplinary } \\
\text { pre-conceptions vs. } \\
\text { expansion }\end{array}$ & $\begin{array}{l}\text { - from technology-only ("computers"), to biology } \\
\text { ("plants") and engineering } \\
\text { - from a computer-science orientation towards } \\
\text { apps, to a more interdisciplinary orientation }\end{array}$ & $\begin{array}{l}\text { - previously had "never really thought they [scientists] } \\
\text { used much of it [coding]" } \\
\text { - from math, technology, and physics to earth \& space } \\
\text { science ("meteorologists"), biology, and chemistry }\end{array}$ & $\begin{array}{l}\text { social (for personal } \\
\text { change) }\end{array}$ \\
\hline
\end{tabular}

\section{Findings from phase 2 (explanation)}

In Phase 2, we analyzed the qualitative data we generated from video recordings, pre- and post-interviews, field notes, and work samples (see Table 3). Per the processes outlined in the methods section, we arrived at the four tensions.

\section{Tension 1: engagement via fun and camaraderie vs. disaffection per anxiety and stress}

Clara and Gabriella were affectively engaged in the project before it officially started, and that engagement persisted at least through the summer vacation. In her postinterview, Clara stated, “... I was really happy because I knew I was gonna work with my best friend on this project, and we were gonna do a really good greenhouse ...." Her happiness, shared with and by Gabriella, persisted as the two enjoyed frequent smiles with successes, small laughs at mistakes, and statements of satisfaction with their "final" product. We use quotations around "final" because Gabriella took the greenhouse home and continued to work on the project, eventually solving an issue with controlling the light strip, likely supported by emotive sources of self-efficacy.

Whereas neither Clara nor Gabriella affectively exhibited very much stress or anxiety, Taylor expressed frustration with her project. As Taylor recalled in the post- interview, "It was frustrating because the codes may be wrong, or ... like when our MCU [microcontroller unit] wasn't working, you have to figure out why it's not working." That is, the complex nature of the greenhouse hardware and software sometimes made problemsolving a complicated process. Fortunately for Taylor, her teammate, Faith, often offered comfort or encouragement when needed. For example, when Taylor was stressed about finding a computer file, she declared, "I. Hate. Everything. About this.". Faith then replied, "No, have a good attitude", and went on to muse, "wow, wow, wow", thereby piquing Taylor's curiosity. Ultimately the frustrating situation was resolved, as the teammates found their computer file, in part due to Faith's exhortative and emotive influences upon Taylor.

On a broader timescale, Taylor expressed anxiety about tests and grades. In her post-interview, when asked about her favorite part of the project, she confessed, "I think I liked [the project] best because I'm not really good at test-taking." Taylor's anxiety about poor performance on tests extended to her grades in general, including grades for the smart-greenhouse project. One manifestation is when Taylor urgently declared, "I really do NOT want to fail." Faith nonchalantly reassured her, "We won't.", to which Taylor relented, "Okay." In these ways, Faith helped to redirect Taylor's potentially

Table 7 Background information for two student-teams (Clara \& Gabriella; Faith \& Taylor)

\begin{tabular}{|c|c|c|c|c|c|c|}
\hline Name & Race \& ethnicity & Gender & Comfort with coding & Skill in coding & Interest in coding \& computer science & Typical grade in science \\
\hline Clara & Latinx & female & very low & medium & very high & $A-$ to $B+$ \\
\hline Gabriella & Latinx & female & medium-high & medium-low & medium-high & $A-$ to $B+$ \\
\hline Faith & White & female & medium & very low & medium-low & B- to $C_{+}$ \\
\hline Taylor & Asian & female & very low & medium-low & medium-low & B- to $\mathrm{C}+$ \\
\hline
\end{tabular}


disaffecting (i.e., disengaging) feelings of stress and anxiety, and, through a combination of fun and camaraderie, affectively re-engage Taylor in the project. Taylor recognized this benefit in her post-interview, stating that "on a test if you don't know the answer, you can't ask anything", as opposed to projects, wherein "if you have something wrong, you can ask a question". Thus, Taylor's experience with a team-based project is reflective of more social views on learning, including social and situational connections with self-efficacy (Bandura, 1977; National Academies of Sciences, Engineering, and Medicine, 2018).

\section{Tension 2: practices as sequential vs. simultaneous}

When considering practices of computation, engineering, and science, teammates reported the three disciplines feeling less connected towards the beginning of the unit and then more connected as the unit progressed. When asked in her follow-up interview about how the practices were or were not overlapping, Clara responded,

... one day, we would do, um, like, [the] science part; one day we would do engineering. At first, we felt like really scheduled to do, like, each task each day. But then, as more time went by, we felt like we were doing like, maybe, like, the three of them at the same time. Like, 10 minutes on this [science] in class, and then 10 minutes on the engineering, and, like, the rest on computation. Or like, all, like, uh, engineering and computation, or like, different mixes during classes. (Post-interview, June 2018)

The notion of "mixes" was echoed by Clara's partner, Gabriella, as noted in this paper's epigraph. In reviewing data from video, at times the scaffolded activities and artifacts appeared to be synergistic. For example, Gabriella once reviewed her notes on humidity and temperature ranges for plants (science), converted the ranges into criteria for the greenhouse design (engineering), then worked with Clara to customize their team's code (computation). This example suggests that Gabriella might be using a direct experience to improve the generality of her self-efficacy for computing (Bandura, 1977), by situating computing in multiple disciplines.

Faith and Taylor had more sequential approaches to practices than did Clara and Gabriella. For example, when Faith was working to make her team's code consistent with engineering design considerations, Taylor was independently completing a worksheet about science concepts. This bifurcation was consistent with one of Faith's responses in her follow-up interview. When asked the same question that Clara was asked about any overlapping of computational, engineering, or science practices, Faith responded,

... with the engineering ... there was, like the, the propeller-type thing [a servo motor with a spinning arm attached]. And it would open the window and close it. And ... then we, like, decided ... when to do that [open or close the window] based on, like, the science we found - the temperature and the humidity and stuff. (Follow-up interview, October 2018)

Despite the presence of computational practices for controlling the servo motor, Faith described only engineering and science in her example. That is, metacognitively Faith was unaware that she was engaging in computational practices, namely to "manage information", which the Massachusetts DLCS includes under the umbrella of abstracting (MA DESE, 2016). This evidence hints at a low strength of self-efficacy developed during the project, as any interdisciplinary connections made during the unit appear to have not persisted past the summer months.

\section{Tension 3: prior experience with coding vs. present application}

For the team of Clara and Gabriella, there was a substantial discrepancy of prior experience with coding, which might have created differential self-efficacy due to performance accomplishments (Bandura, 1977). Clara had participated in a Girls Who Code club. On the other hand, Gabriella claimed to have never done coding before the start of the smart-greenhouse project. Nonetheless, there were times when Clara's expertise had gaps in taking skills from App Inventor and applying them in MicroPython. For example, in App Inventor the comments appear as rounded rectangles with yellow backgrounds and various colors of trim. However, in the EsPy IDE for MicroPython (i.e., the program in which students wrote their code), commented sections of code lack any shape or trim, and they appear as green text against a shared background color (black). When Clara was asked by an observer-as-participant (Creswell, 2013) to think aloud about why some of her team's code was green, she replied, "I don't know." In fact, it was Gabriella who first answered the question, noticing that the hashtag symbol (\#), being intended as an abstract placeholder for some value (in this case, temperature), had turned the remainder of the line into a comment, and was therefore being ignored by the Wio Link microcontroller unit. This one character (\#), misinterpreted by the more experienced coder, would have nullified all temperature-based controls, had the participantobserver not called the issue to attention. In this case, the temporal persistence of Clara's block-based coding 
experience resulted in a disadvantageous behavior, which was mitigated by the emotional arousal of excitement for the project and comfort in working with a friend.

Faith and Taylor had similar backgrounds in coding, namely a technology literacy course in sixth grade. However, neither teammate remembered much from their experience doing block-based coding in Scratch, resulting in a low magnitude of self-efficacy from performance accomplishments. According to Taylor, the main activity from sixth grade was based on "a worksheet-type thing online where they would teach you how to kind of get the gist of [coding]." When asked if the activity involved any problem-solving, Taylor said, "No." On the other hand, the smartgreenhouse unit frequently involved problem-solving. In her post-interview, Faith stated, "I learned that coding takes a lot of determination and perseverance and optimism because things are going to go wrong a lot." Faith then went on to discuss troubleshooting various spelling or syntax errors. Having worked with block-based coding in the distinct social and situational context of sixth grade, Faith and Taylor had to adjust their understanding of coding when using a text-based approach in eighth grade. Though surprised by the unexpected difficulties, Faith and Taylor adapted to the new situation, without being impeded by any strong attachments to their previous coding experiences. Thus, Faith and Taylor were supported by emotional arousal in similar ways as Clara and Gabriella.

\section{Tension 4: disciplinary pre-conceptions vs. expansion}

Clara, Gabriella, Faith, and Taylor - like many of their classmates - entered the smart-greenhouse unit with pre-conceptions of coding as primarily in the domains of computer science, technology, and physics. In their postinterviews, they expressed an awareness of coding for curriculum-proximal topics (biology and engineering) and for curriculum-distal topics (chemistry and earth \& space science). As the curriculum-proximal disciplinary expansions are straightforward, we now discuss the curriculum-distal topics.

For chemistry, in her post-interview Taylor made connections with steam, chemical reactions, and weather, which were not focal elements of the smart-greenhouse project:

If we're doing chemicals and reactions and stuff, you could have a temperature sensor above it. When you're pouring the water and the steam may be able to tie in to what the temperature of the water may be ... . I think meteorologists probably do use them when they're trying to figure out the weather, and what the weather may be like outside right now.
Taylor perceived the pluridisciplinary possibilities of the curriculum, without knowing its manifestations in the research team's work with partners in different schools and grade levels (Asante et al., 2021). This perception shows promise for the generality of Taylor's self-efficacy for computation in disciplines.

Such disciplinary expansions increase the likelihood of youth engaging in practices of computation, which may subsequently develop their self-efficacy. As the field of computer science works to improve representation and equity, more and broader pathways to participation show promise for closing gaps in opportunity (Blikstein, 2018; S. L. Rodriguez \& Lehman, 2017).

\section{Summary}

Our findings illustrate some tensions that eighth grade students in a required environmental science class experienced as they engaged in practices of computation, engineering, and science during a smart-greenhouse project. As detailed above, the intervention supported the generality of self-efficacy for computation in disciplines, through social contexts and emotive sources. Understanding these processes of growth, especially in more pluridisciplinary ways, can support the design of more equitable learning environments, as we elaborate in the Discussion.

\section{Discussion}

In this paper, we presented findings from an in-schooltime, smart-greenhouse intervention with grade eight students in two required environmental science classes. We highlighted four main tensions that emerged from our data analysis, in ways that spanned interest, engagement, and self-efficacy. In this section we explore more deeply the connections with theory, and how those connections relate to practice.

\section{Implications for theory and practice Self-efficacy theory in education}

In their review of research on self-efficacy theory in education, Schunk and DiBenedetto (2016) identified six types of self-efficacy. In this section, given our studentteam unit of analysis, we focused on three types: self-efficacy for learning, self-efficacy for self-regulated learning, and collective self-efficacy. In addition to identifying types of self-efficacy, Schunk and DiBenedetto (2016) highlighted four directions in need of more research. The current paper addresses three of the four directions, and ongoing work (Asante et al., 2021) addresses the fourth direction, out-of-school settings. Interactions with the cultural and linguistic diversity of participants from Mills City relate to cultural backgrounds; the connections with peer-, school-, family-, and communityrelated matters connects with contextual influences; and 
our use of observations, think alouds, and traces explores the dynamic nature of self-efficacy.

Along with the Western/non-Western cultural dialectic emphasized by Schunk and DiBenedetto (2016), our work adds a Global North/South dialectic. For the former, insight comes from Taylor's anxiety towards individualistic works and her excitement for collectivist projects. This attitude was evident from the previously cited excerpt from her post-interview, that "on a test if you don't know the answer, you can't ask anything", but in projects, "if you have something wrong, you can ask a question." For the Global North/South dialectic, Clara's emotional arousal for coding is due in part to her visits to her homeland of Guatemala, where she teaches near-peers about coding. Her work in the Global South highlights some diversity that might other get hidden by the umbrella US Census category of "Hispanic/Latino", which hides factors related to Western/non-Western and Global North/South cultural backgrounds (National Academies of Sciences, Engineering, and Medicine, 2018).

Taylor's test aversion and project affinity also connect with contextual influences, namely those related to school and peers. Within a broader social context where opportunities for computing education are inequitably more available through electives, clubs, and camps, especially in more affluent communities (Blikstein, 2018), our study addresses the affordances and limitations of embedding computation in science classes that all students can access. Our findings echo those of Wei et al. (2021), in that peer support and school accountability might be harmonized through communal preparations and individual products. In our case, the team preparations preceded a community showcase, during which students were individually responsible for answering visitors' questions. With only a participation grade attached, students felt incentivized to prepare for the showcase, without the added anxiety of a major grade. Our findings with family- and community-related influences are much more anecdotal, limited to slight evidence of students using the plants in their home culture's cuisine, or making connections with parents and grandparents with cooking, landscaping, and gardening expertise. These connections merit further exploration, which we do more in our out-of-school-time implementations (Asante et al., 2021).

Though our findings speak of observations in a more holistic sense, the data sources include the think alouds and traces encouraged by Schunk and DiBenedetto (2016) for understanding the dynamic nature of selfefficacy. For think alouds, we had observers-asparticipants (Creswell, 2013) ask probing questions of student-teams during their work-time. Our version of traces, or "observable measures that students create as they engage in tasks" (Schunk \& DiBenedetto, 2016, p.
50), include screen recordings in which students can be seen making and correcting errors (debugging), as well as conceptualizing and manipulating environmental variables of interest (abstracting). These artifacts lend insight to how technology can facilitate a trial-and-error approach that can be supported in varying degrees and ways by self-efficacy for computing in disciplines.

\section{Cognitive development and self-efficacy}

Bandura (1993) described four processes through which self-efficacy leads to cognitive development. Tension 1 (engagement $\leftrightarrow$ disaffection) primarily relates to affective and motivational processes; Tensions 2-4 (sequential practices $\leftrightarrow$ simultaneous practices, experience $\leftrightarrow$ application, and pre-conceptions $\leftrightarrow$ expansion) pertain to cognitive processes.

Bandura (1993) described affective processes of selfefficacy as acting in inhibitory ways. In one sense, the fun and camaraderie of Tension 1 could be seen as antidotes to the toxic nature of anxiety and stress. Also, the project-based nature of the unit circumvents test anxiety, a concern for Taylor and likely additional students. Further, a team-based approach develops adolescents' collective self-efficacy. Improved affect towards computation, engineering, and science could increase the chances of adolescents choosing camps, classes, clubs, or careers in the fields of science, technology, engineering, and mathematics (Allen et al., 2019; Fortus \& Touitou, 2021; Maltese \& Tai, 2011; Tytler \& Osborne, 2012).

With regards to motivation processes, positive peer pressure from a partner can address Bandura's (1993) subprocess of cognized goals, or shorter-term targets within a longer-term endeavor. Further, teammates can help moderate self-reactive influences, as illustrated by the example of Faith encouraging Taylor that "We won't [fail]." Finally, proactive control of motivation is enhanced when teammates set ambitious goals for each other, as shown when Clara and Gabriella went beyond mere functionality of their greenhouse to consider aesthetics.

\section{Implications for design}

Our study demonstrates the robustness of designing for pluridisciplinarity, in order to leverage students' interests to promote their engagement in practices of $\mathrm{CT}$ and STEM. Interest is especially important for elementaryand middle-school learners, particularly for closing equity gaps in participation and attainment (Allen et al., 2019; Maltese \& Tai, 2011; Tytler \& Osborne, 2012). Further, the broader the interests that can be drawn upon, the more resources students can bring to collective sense-making (Lee \& Malyn-Smith, 2020). In the present study, like the four focal students, many youth were interested in plants and aesthetics, which helped 
them to initially engage and provided motivation to make sense of relationships between code, data, and their physical system. More monodisciplinary framings could be extended in pluridisciplinary ways, using our conceptual framework as a basis for disciplinary expansion. In the smart-greenhouse project, a technology-only disciplinary approach would have included the sensors, actuators, and microcontrollers; such a model would have failed to engage students' demonstrated interests around arts (aesthetics of LED light strips), biology (plants), construction (of the greenhouse and how it supported the technologies), and so on.

At the same time as we urge a move towards pluridisciplinary, we also emphasize the importance of synergies between disciplines, detailed in the "Curriculum Design" section. Careful planning of concepts and practices across disciplines can result in synergies between those disciplines (Century et al., 2020; Yin et al., 2020). Much alignment between CT and STEM has already been documented in major standards and frameworks (K12cs.org, 2016; Lee \& Malyn-Smith, 2020; NGSS Lead States, 2013). More work is needed to faithfully integrate arts into STEM, in ways that go beyond subservient and coequal models, in pluralistic ways that are more affective and social (Bresler, 1995). In particular, the LED strips of the smart-greenhouse project represented a harmony of arts (aesthetics of color-coordination and animations), biology (how plants respond to different wavelengths of light), physics (relationship between distance and flux), and more. This harmony inspired some students to take their greenhouses home, even though the school year was about to end.

In sum, the present paper extends Bandura's (1977, 1993, 2001) theorizing on self-efficacy, in directions of need identified by Schunk and DiBenedetto (2016). It also builds on and extends previous work in more monodisciplinary settings, and addresses key elements of newer consensus frameworks for integrating CT in STEM disciplines.

\section{Limitations and future directions}

We recognize that our findings and implications are situated within two classrooms, and primarily two student dyads, of one school in Mills City. Nonetheless, the culturally and linguistically diverse nature of the setting offers broader understandings than studies that have been conducted in more homogenous environments. Further iterations with the current school, extension to a second middle school in Mills City, and expansions in the Western US and beyond will deepen and broaden our understanding of embedding $\mathrm{CT}$ in required $\mathrm{K}-12$ classes (Asante et al., 2021). Also, a transition to BBC micro:bit will increase accessibility in modality and hardware (as block- and cloud-based).
Another limitation relates to data generation, namely that participant-researchers sometimes acted as teaching assistants, which limits the transferability of our findings. Though triangulation of data helped us to more broadly understand the lived experiences of adolescents, future observation protocols will be revised to promote transferability, especially to settings where only one or two adults are facilitating per classroom. Recently published formative and summative instruments, more parsimonious than those used in the present study, could aid in a richer data corpus without overly imposing upon students' and teachers' time and energy (e.g., Kukul \& Karatas, 2019; Yin et al., 2020).

Since the iteration in this paper, the research team has continued to honor the pluridisciplinary nature of the project, in ways that promote understanding complex systems, one of five CT integration elements that emerged from a workshop of 54 researchers and practitioners across grade levels and disciplines (Lee \& MalynSmith, 2020, p. 10). To this point we have tended to focus on perspectives of practitioners more than students (Asante et al., 2021; $\mathrm{Xu}, 2019$ ); this study and future work shows promise for deeper understandings of students. Ultimately, we hope to arrive at a more nuanced and dialectical design for the smart-greenhouse and similarly pluridisciplinary projects.

\section{Conclusion}

The present study provides insight into the shorter-term mechanisms of self-efficacy theory, which has been shown to connect with mediators and outcomes such as student engagement, achievement, course choice, and career selection (Bandura, 1993, 2001; Schunk \& DiBenedetto, 2016). This paper enriches the work that has been done in prepost style studies, and it addresses the need for research on self-efficacy in culturally and linguistically diverse settings (Schunk \& DiBenedetto, 2016).

Embedding computational thinking and practices in required K-12 classes remains a high priority for educational designers. It will likely remain a priority for the foreseeable future, as "literally all industry sectors are impacted by technology innovations" (Lee \& MalynSmith, 2020, p. 17). The present study offers findings that suggest how educational designers and practitioners can use learning environments to leverage interest in supporting student engagement and self-efficacy for computation. Our understandings will inform our future design and should prove useful to designers in similar settings. As ubiquitous computing is "all mixed together" within and between traditional disciplinary boundaries, the time is ripe for pluridisciplinary spaces - such as projects with smart greenhouses - as environments for growing computational literacy. 


\section{Abbreviations}

CS: Computer science; CT: Computational thinking; ELA: English Language Arts; IDE: Integrated development environment; IUSE: Innovation in Urban Science Education (lab / research team); K-12: Kindergarten through 12th grade; MA DESE: Massachusetts Department of Elementary and Secondary Education; MA DLCS: Massachusetts Digital Literacy and Computer Science framework; MCU: Microcontroller unit; NGSS: Next Generation Science Standards; QUAL: Qualitative; QUAN: Quantitative; SPSS ${ }^{\bullet}$ Statistical Package for Social Sciences; STEM: Science, technology, engineering, and mathematics; STEM+C / STEM-C: science, technology, engineering, and mathematics, with computing; US: United States

\section{Acknowledgements}

The authors thank the participating youth and adults, as well as their colleagues in the Innovation in Urban Science Education (IUSE) lab.

\section{Authors' contributions}

DJ led the research design, data analysis, and manuscript preparation. YC and QM assisted with data analysis and provided feedback on manuscript drafts. YC also edited several passages of text. YX designed the curriculum and led professional development sessions. All authors approved the final manuscript.

\section{Funding}

This work was supported by a Collaborative Fellows grant from Boston College, which also approved the research design through its Institutional Review Board. The analysis, interpretation, and writing were performed independently of the Institutional Review Board, and therefore do not necessarily reflect official views or opinions of Boston College or its Collaborative Fellows grant program.

\section{Availability of data and materials}

Data sources are not publicly available, due to privacy and confidentiality concerns per our agreement with the Boston College Institutional Review Board.

\section{Declarations}

\section{Ethics approval and consent to participate}

This study was approved by the Institutional Review Board of Boston College. All participating teachers and parents/guardians completed consent forms. All participating students completed assent forms.

\section{Consent for publication}

The participants gave consent for publications that maintain privacy and confidentiality (including, but not limited to, the use of pseudonyms and rounding of school-level data).

\section{Competing interests}

The authors declare that they have no competing interests.

\section{Author details}

'Boston College, 140 Commonwealth Avenue, Campion Hall \#119A, Chestnut Hill, MA 02467, USA. ${ }^{2}$ Shanghai Normal University, No.100 Guilin Rd., Shanghai 200234, China.

Received: 18 August 2021 Accepted: 22 January 2022 Published online: 01 February 2022

\section{References}

Allen, P. J., Chang, R., Gorrall, B. K., Waggenspack, L., Fukuda, E., Little, T. D., \& Noam, G. G. (2019). From quality to outcomes: A national study of afterschool STEM programming. International Journal of STEM Education, 6(1), 37. https://doi.org/10.1186/s40594-019-0191-2.

Asante, C. K., Semerjian, A., Xu, P., Jackson, D., Cheng, Y., Chasen, A., ... Broadstone, M. (2021). An integrated STEM and computing curriculum for the human-technology frontier: The case of a smart greenhouse. Connected Science Learning, 3(2). Retrieved Jan. 30, 2022, from https://www.nsta.org/ connected-science-learning/connected-science-learning-march-april-2021/ integrated-stem-and.
Bandura, A. (1977). Self-efficacy: Toward a unifying theory of behavioral change. Psychological Review, 84(2), 191-215. https://doi.org/10.1037/0033-295X.84.2.1 91.

Bandura, A. (1993). Perceived self-efficacy in cognitive development and functioning. Educational Psychologist, 28(2), 117-148. https://doi.org/10.1207/ s15326985ep2802_3.

Bandura, A. (2001). Social cognitive theory: An agentic perspective. Annual Review of Psychology, 52(1), 1-26. https://doi.org/10.1146/annurev.psych.52.1.1.

Bandura, A. (2006). Guide for constructing self-efficacy scales. In Self-efficacy beliefs of adolescents, (pp. 307-337). Information age publishing. https://doi.org/10.1 017/CBO9781107415324.004.

Birsan, J., Stavarache, D., Dascalu, M.-I., Pavaloiu, I. B., \& Neagu Trocmaer, A. M. (2017). Internet of things in education: A case study for learning agriculture Proceedings of the 13th international scientific conference Elearning and software for education, 450-457. https://doi.org/10.12753/2066-026X-13-131.

Blikstein, P. (2018). Pre-college computer science education: A survey of the field. Google LLC. Retrieved Jan. 30, 2022, from https://goo.gl/gmS1Vm.

Boekaerts, M. (2016). Engagement as an inherent aspect of the learning process. Learning and Instruction, 43, 76-83. https://doi.org/10.1016/j.learninstruc.2016. 02.001.

Bresler, L. (1995). The subservient, co-equal, affective, and social integration styles and their implications for the arts. Arts Education Policy Review, 96(5), 31-37. https://doi.org/10.1080/10632913.1995.9934564

Century, J., Ferris, K. A., \& Zuo, H. (2020). Finding time for computer science in the elementary school day: A quasi-experimental study of a transdisciplinary problem-based learning approach. International Journal of STEM Education, 7(1), 20. https://doi.org/10.1186/s40594-020-00218-3.

Chevalier, M., Giang, C., Piatti, A., \& Mondada, F. (2020). Fostering computational thinking through educational robotics: A model for creative computational problem solving. International Journal of STEM Education, 7(1), 39. https://doi. org/10.1186/s40594-020-00238-z.

Christenson, S. L., Wylie, C., \& Reschly, A. L. (2012). Handbook of research on student engagement. https://doi.org/10.1007/978-1-4614-2018-7 https:// www.researchgate.net/profile/Azkananda-Widiasani/publication/310773130_ Handbook_of_Student_Engagement/links/5836a0dd08aed45931 c772b7/Ha ndbook-of-Student-Engagement.pdf.

Christopher, B. (2013, Jun. 4). Aquaponics sprout a business - Kijani Grows. SFGA TE. Retrieved Jan. 30, 2022, from https://www.sfgate.com/homeandgarden/a rticle/Aquaponics-sprout-a-business-Kijani-Grows-4576219.php.

Creswell, J. W. (2013). Qualitative inquiry and research design: Choosing among five approaches (3rd ed.). Los Angeles: Sage Publications.

Creswell, J. W., \& Plano Clark, V. L. (2018). Designing and conducting mixed methods research (3rd ed.). Los Angeles: SAGE.

Denning, P. J. (2017). Remaining trouble spots with computational thinking. Communications of the ACM, 60(6), 33-39. https://doi.org/10.1145/2998438.

Erickson, F. (2006). Definition and analysis of data from videotape: Some research procedures and their rationales. In J. L. Green, G. Camilli, P. B. Elmore, A. Skukauskaite, \& E. Grace (Eds.), Handbook of complementary methods in education research (pp. 177-191). Mahwah: Lawrence Erlbaum Associates.

Fortus, D., \& Touitou, I. (2021). Changes to students' motivation to learn science. Disciplinary and Interdisciplinary Science Education Research, 3(1), 1. https://doi. org/10.1186/s43031-020-00029-0.

Fredricks, J. A., Blumenfeld, P. C., \& Paris, A. H. (2004). School engagement: Potential of the concept, state of the evidence. Review of Educational Research, 74(1), 59-109. https://doi.org/10.3102/00346543074001059.

Fredricks, J. A., Wang, M. T., Linn, J. S., Hofkens, T. L., Sung, H., Parr, A., \& Allerton, J. (2016). Using qualitative methods to develop a survey measure of math and science engagement. Learning and Instruction, 43, 5-15. https://doi.org/1 0.1016/j.learninstruc.2016.01.009.

Gendreau Chakarov, A., Recker, M., Jacobs, J., Van Horne, K., \& Sumner, T. (2019). Designing a middle school science curriculum that integrates computational thinking and sensor technology. Proceedings of the 50th ACM technical symposium on computer science education (SIGCSE '19), 818-824. https://doi. org $/ 10.1145 / 3287324.3287476$.

Grover, S., \& Pea, R. (2013). Computational thinking in K-12: A review of the state of the field. Educational Researcher, 42(1), 38-43. https://doi.org/10.3102/ $0013189 \times 12463051$.

Grover, S., \& Pea, R. (2018). Computational thinking: A competency whose time has come. In S. Sentance, E. Barendsen, \& C. Schulte (Eds.), Computer science education: Perspectives on teaching and learning in school (pp. 19-39). 
Bloomsbury Academic. http://hub.mspnet.org/index.cfm/33300. https://doi. org/10.5040/9781350057142.ch-003.

Hadad, R., Thomas, K., Kachovska, M., \& Yin, Y. (2020). Practicing formative assessment for computational thinking in making environments. Journal of Science Education and Technology, 29(1), 162-173. https://doi.org/10.1007/s1 0956-019-09796-6.

Hernandez, E. (2018). How CU Boulder is growing greens for a campus dining hall without soil. Colorado Daily. Retrieved Jan. 30, 2022, from https://www.da ilycamera.com/2018/01/12/how-cu-boulder-is-growing-greens-for-a-campusdininghall-without-soil/,

Hidi, S., \& Renninger, K. A. (2006). The four-phase model of interest development. Educational Psychologist, 41(2), 111-127. https://doi.org/10.1207/s1532 6985ep4102_4.

Hofstetter, R. (2012). Educational sciences: Evolutions of a Pluridisciplinary discipline at the crossroads of other disciplinary and professional fields (20th Century). British Journal of Educational Studies, 60(4), 317-335. https://doi. org/10.1080/00071005.2012.729666.

Järvelä, S., \& Renninger, K. A. (2014). Designing for learning: Interest, motivation, and engagement. In R. K. Sawyer (Ed.), The Cambridge handbook of the learning sciences, (2nd ed., pp. 668-685). Cambridge University Press. https:// doi.org/10.1017/CBO9781139519526.040.

K12cs.org. (2016). K-12 Computer Science Framework. Retrieved Jan. 30, 2022, from http://k12cs.org/wp-content/uploads/2016/09/K-12-Computer-ScienceFramework.pdf

Kukul, V., \& Karatas, S. (2019). Computational thinking self-efficacy scale: Development, validity and reliability. Informatics in Education, 18(1), 151-164. https://doi.org/10.15388/infedu.2019.07.

Ladson-Billings, G. (1995). Toward a theory of culturally relevant pedagogy. American Educational Research Journal, 32(3), 465-491. https://doi.org/10.23 07/1163320.

Lee, I., \& Malyn-Smith, J. (2020). Computational thinking integration patterns along the framework defining computational thinking from a disciplinary perspective. Journal of Science Education and Technology, 29(1), 9-18. https:// doi.org/10.1007/s10956-019-09802-x.

Luo, T., So, W. W. M., Wan, Z. H., \& Li, W. C. (2021). STEM stereotypes predict students' STEM career interest via self-efficacy and outcome expectations. International Journal of STEM Education, 8(1), 36. https://doi.org/10.1186/s4 0594-021-00295-y.

Maltese, A. V., \& Tai, R. H. (2011). Pipeline persistence: Examining the association of educational experiences with earned degrees in STEM among U.S. students. Science Education, 95(5), 877-907. https://doi.org/1 $0.1002 /$ sce. 20441

Massachusetts Department of Elementary and Secondary Education (2016). 2016 Massachusetts Digital Literacy and Computer Science (DLCS) curriculum framework (June). https://doi.org/10.1109/QOMEX.2010.5516300.

Miles, M. B., Huberman, M. A., \& Saldaña, J. (2014). Qualitative data analysis: A methods sourcebook (3rd ed.). Los Angeles: Sage Publications.

National Academies of Sciences, Engineering, and Medicine (2018). How people learn II. In Learners, contexts, and cultures. The National Academies Press. https://doi.org/10.17226/24783.

NGSS Lead States (2013). Next generation science standards: For states, by states. Washington, DC: The National Academies Press.

Nguyen, U., \& Riegle-Crumb, C. (2021). Who is a scientist? The relationship between counter-stereotypical beliefs about scientists and the STEM major intentions of black and Latinx male and female students. International Journal of STEM Education, 8(1), 28. https://doi.org/10.1186/s40594-021-00288-x.

Papert, S. (1980). Mindstorms: Children, computers, and powerful ideas. New York: Basic Books.

Rodriguez, A. J. (2015). What about a dimension of engagement, equity, and diversity practices? A critique of the next generation science standards. Journal of Research in Science Teaching, 52(7), 1031-1051. https://doi.org/10.1 002/tea.21232.

Rodriguez, S. L., \& Lehman, K. (2017). Developing the next generation of diverse computer scientists: The need for enhanced, intersectional computing identity theory. Computer Science Education, 27(3-4), 229-247. https://doi org/10.1080/08993408.2018.1457899.

Rosen, J. H., Moore, R., \& Usselman, M. (2016). Middle grades STEM innovation and design courses: From data to design (P12 Resource Exchange). 123rd ASEE Annual Conference and Exposition. https://doi.org/10.18260/p.25718.

Saldaña, J. (2009). The coding manual for qualitative researchers. Thousand Oaks: Sage Publications, Inc.
Schunk, D. H., \& DiBenedetto, M. K. (2016). Self-efficacy theory in education. In K. R. Wentzel, \& D. B. Miele (Eds.), Handbook of motivation at school, (2nd ed., pp. 34-54). Routledge. https://doi.org/10.4324/9781315773384.ch3.

Shin, N., Bowers, J., Krajcik, J., \& Damelin, D. (2021). Promoting computational thinking through project-based learning. Disciplinary and Interdisciplinary Science Education Research, 3(1), 7. https:/doi.org/10.1186/s43031-021-00033-y.

Tucker-Raymond, E., Puttick, G., Cassidy, M., Harteveld, C., \& Troiano, G. M. (2019). "I broke your game!": Critique among middle schoolers designing computer games about climate change. International Journal of STEM Education, 6(1), 41. https://doi.org/10.1186/s40594-019-0194-z.

Tytler, R., \& Osborne, J. (2012). Student attitudes and aspirations towards science. In B. J. Fraser, K. G. Tobin, \& C. J. McRobbie (Eds.), Second international handbook of science education (pp. 597-625). Springer. https://doi.org/10.1 007/978-1-4020-9041-7_41.

Vogel, S., Santo, R., \& Ching, D. (2017). Visions of computer science education: Unpacking arguments for and projected impacts of CS4All initiatives. Proceedings of the 2017 ACM SIGCSE technical symposium on computer science education - SIGCSE '17, 609-614. https://doi.org/10.1145/3017680.3017755.

Vongkulluksn, V. W., Matewos, A. M., Sinatra, G. M., \& Marsh, J. A. (2018). Motivational factors in makerspaces: A mixed methods study of elementary school students' situational interest, self-efficacy, and achievement emotions. International Journal of STEM Education, 5(1), 43. https://doi.org/10.1186/s4 0594-018-0129-0.

Voogt, J., Fisser, P., Good, J., Mishra, P., \& Yadav, A. (2015). Computational thinking in compulsory education: Towards an agenda for research and practice. Education and Information Technologies, 20(4), 715-728. https://doi.org/10.1 007/s10639-015-9412-6

Wei, X., Lin, L., Meng, N., Tan, W., Kong, S.-C., \& Kinshuk (2021). The effectiveness of partial pair programming on elementary school students' computational thinking skills and self-efficacy. Computers \& Education, 160, 104023. https:// doi.org/10.1016/j.compedu.2020.104023.

Wilensky, U., Brady, C. E., \& Horn, M. S. (2014). Fostering computational literacy in science classrooms. Communications of the ACM, 57(8), 24-28. https://doi. org/10.1145/2633031.

Wing, J. M. (2006). Computational thinking. Communications of the ACM, 49(3), 33-35. https://doi.org/10.1145/1118178.1118215.

$\mathrm{Xu}, \mathrm{Y}$. (2019). Extending text-based programming languages to embed computing into middle school science classrooms. Chestnut Hill: Boston College [unpublished doctoral dissertation].

Yin, Y., Hadad, R., Tang, X., \& Lin, Q. (2020). Improving and assessing computational thinking in maker activities: The integration with physics and engineering learning. Journal of Science Education and Technology, 29(2), 189-214. https://doi.org/10.1007/s10956-019-09794-8.

\section{Publisher's Note}

Springer Nature remains neutral with regard to jurisdictional claims in published maps and institutional affiliations.

\section{Submit your manuscript to a SpringerOpen ${ }^{\circ}$ journal and benefit from:}

- Convenient online submission

- Rigorous peer review

- Open access: articles freely available online

- High visibility within the field

- Retaining the copyright to your article

Submit your next manuscript at $\boldsymbol{\nabla}$ springeropen.com 